\title{
Uma boa mãe de família chicana: a práxis cotidiana na série Brown Angel Mysteries, de Lucha Corpi
}

Carla Portilho ${ }^{1}$

Recebido em 26 jun 2012 - Aprovado em 26 set 2012

\section{Resumo}

As práticas cotidianas marcam presença na série policial Brown Angel Mysteries, da escritora chicana Lucha Corpi. Com base na teoria de Michel de Certeau sobre a práxis cotidiana, desenvolvida em A invenção do cotidiano, este artigo propõe-se a discutir de que modo os usos e fazeres do dia-a-dia, como o trabalho doméstico e os mitos e crenças herdados da tradição mexicana, representam um meio de opor resistência às práticas socioculturais dominantes, assim como seu papel político como uma tática por meio da qual as comunidades marginalizadas representadas buscam se (re)apropriar de um espaço cultural, político e socioeconômico, adquirindo novos significados no espaço de confron to entre o centro de poder e a periferia. Por meio da caracterização da protagonista da série, Gloria Damasco, Lucha Corpi abre o gênero policial à diversidade cultural, oferecendo uma percepção não-eurocên trica da realidade, que aceita como real o conhecimento que vem de fontes intangiveis como os sonhos, as visões, a intuição e a percepção extra-sensorial. Essas experiências não-racionais se entrelaçam à presença de mitos fundamentais para a cultura e memória chicanas como La Llorona e La Malinche - para apresentar um enredo policial que subverte a lógica cartesiana da ficção detetivesca tradicional.

1 Todas as traduções foram feitas pela autora.

Palavras-chave: literatura policial chicana; práxis cotidiana; mitos 
Em A invenção do cotidiano, Michel de Certeau se propôs a estudar os usos e fazeres do homem comum como uma forma de oferecer resistência às práticas sócio-culturais dominantes. Distinguiu as práticas cotidianas entre estratégias e táticas, definindo estratégias como uma manipulação das relações de força que possibilitam o estabelecimento de um lugar próprio de poder, e táticas como as ações determinadas pela ausência de poder, um "não-lugar" que só se realiza no espaço do Outro e em relação a ele, aproveitando-se das circunstâncias para alcançar qualquer possibilidade de ganho (CERTEAU, 1994, p.97-102). São maneiras outras de fazer, que imprimem novos significados a códigos pré-estabelecidos, re-significando essas práticas e funcionando como uma cultura diferente dentro da cultura dominante. Enquanto as estratégias são sustentadas pelo poder, as táticas visam a resistir a esse mesmo poder, ou seja, apenas aparentam conformar-se a ele.

Assim, partindo-se do pressuposto de que as práticas cotidianas podem constituir uma forma de resistência de culturas subalternas ao poder dominante, sua presença em romances produzidos fora do centro hegemônico adquire um propósito político, constituindo uma tática por meio da qual as comunidades marginalizadas representadas buscam se (re)apropriar de um espaço cultural, político e sócio-econômico, adquirindo novos significados no espaço de confronto entre o centro de poder e a periferia - o homem comum aproveita as brechas que se abrem no sistema dominante para buscar seu próprio espaço. Tal característica é marcante na obra de Lucha Corpi, criadora da primeira detetive feminina da literatura chicana, Gloria Damasco, protagonista da série Brown Angel Mysteries. No âmbito deste ensaio, escolheu-se trabalhar com duas das práticas cotidianas representadas na série: o envolvimento de Gloria com o trabalho doméstico, incluindo tanto os cuidados com a casa quanto com a família, e sua relação com os mitos e crenças da cultura chicana.

Gloria Damasco é uma personagem sui generis. No início da série, ela é uma jovem mãe de família chicana que está em Los Angeles participando da Moratorium March, e que, ao fugir do confronto com a polícia e da confusão generalizada que se instala na cidade, encontra o corpo de um menino assassinado. Emocionalmente envolvida no caso, ela se vê compelida a investigar não apenas o crime em si e seu autor, mas as causas que teriam levado a essa atrocidade. No entanto, dezoito anos se passarão antes que Gloria tenha a chance de elucidar o mistério. No ano em que acontece o crime, ela investiga o caso e colabora com a polícia, mas acaba por abrir mão de desvendar o mistério em troca de manter a harmonia no seu casamento e os cuidados com a filha pequena. Somente quando as circunstâncias da vida a deixam sozinha - seu marido morre e a filha vai para a univer- 
sidade - ela decide retomar o trabalho de investigar o caso que havia abandonado tantos anos antes.

No caso de Gloria, a prática de cuidar da casa e da família se mostra em sua rotina de detetive justamente por meio de suas renúncias - ela renuncia à investigação do crime em nome de manter a tradição chicana, que reza que a primeira obrigação da mulher diz respeito ao seu marido e à sua família. Por outro lado, é exatamente essa renúncia inicial à investigação, que retarda a solução do caso por quase duas décadas, que define o perfil de Gloria como detetive. Ao longo da série, ela deixa de ser uma detetive amadora, que investiga o caso usando apenas seu bom senso, sua intuição e sua rede de contatos para se tornar uma detetive profissional, treinada para utilizar armas de fogo e enfrentar situações de perigo, distanciando-se, portanto, do modelo original representado pela Miss Marple de Agatha Christie e acercando-se dos detetives hard-boiled do romance noir.

Em 1970, ano que acontece o crime, Gloria investiga o caso de forma amadora, levada pela perturbação causada pela morte do menino cujo corpo ela descobre na rua. Envolvida afetivamente no caso, ela colabora com a polícia, estuda o caso e acaba por montar um bom dossiê referente aos envolvidos. Entretanto, pressionada pelo marido a escolher entre a família e o prosseguimento das investigações, Gloria abre mão de desvendar o mistério. Judy Maloof enfatiza que Darío, o marido de Gloria, usa chantagem emocional quando verbaliza o seguinte ultimato (MALOOF, 2006):

I know I shouldn't have gone through your papers [...] but I needed to find out what it was you were risking your health and happiness for. (...) You never told me that you were held at gunpoint. What has happened to you, Gloria? Is tinkering with this case so important to you that you would risk everything for it? (...) I've never told you what to do. [...] And I never kept you from doing what you thought was best. But you've never been reckless before. Now you're endangering your life, with no regard for Tania's well-being or mine. (...) I will not keep you from going on with your investigation. (...) But think about this. What is more important for you, solving this case or keeping our marriage and family together? This is something you alone will have to decide. (CORPI, 1992, p.121)

A sensação de estar roubando tempo da família para se dedicar ao trabalho é uma questão inexistente para os detetives homens, mas essencial para as mulheres, sobretudo as chicanas, cuja obrigação primordial diz respeito ao bem-estar do marido e dos filhos. Por vezes, essa condição feminina se assemelha a uma armadilha, como na seguinte passagem do romance:

Then her thoughts drifted over the many mothers who had been involved in this case. [...] They seemed to be caught in a game where all the main players were men, and the losers were all women and their children. When this was over - as 
in time of war and subsequent peace - the women would have to swallow their grief and their shame. They would have to comfort and support each other, then begin the long and painful task of rebuilding their lives. (CORPI, 1992, p.170-171)

Desse modo, dezoito anos se passam antes que seja possível a Gloria destrinchar o caso. Ela só volta a investigar o mistério em 1988, após a morte de seu marido e a ida da filha para a universidade. Nesta segunda parte do romance, ela já está livre de suas obrigações para com a sociedade, em particular a sociedade chicana, centrada na unidade familiar. A viuvez representa a conquista da liberdade - a mulher viúva é ainda mais livre do que a divorciada, já que esta é responsabilizada pelo fim do casamento.

Kimberly Dilley aponta que o detetive masculino tradicional não tem tempo para uma esposa e filhos, mas nunca é cobrado em relação a isso. Por outro lado, a detetive feminina sofre pressões da sociedade para casar e constituir uma família, uma vez que esse é considerado o papel fundamental da mulher na sociedade. Seu trabalho como investigadora particular é visto como a principal causa de rupturas nos casamentos e como fonte constante de conflitos para o casal. As mulheres divorciadas estão livres de grande parte da pressão exercida pela sociedade sobre as mulheres solteiras para 'agarrar' um marido - é certo que são consideradas culpadas pelo fracasso da relação, mas ao menos recebem aprovação social por terem seguido o caminho do casamento (DILLEY, 1998, p.26-27). Ela ressalta ainda que os relacionamentos mais satisfatórios mostrados nos romances policiais femininos são aqueles em que os papéis e expectativas tradicionais são continuamente renegociados e compreendidos como definições sociais, ao invés de qualidades inatas (DILLEY, 1998, p.29).

Gloria volta a se envolver afetivamente ao conhecer Justin Escobar, um detetive particular contratado por sua mãe para protegê-la quando ela decide reabrir seus arquivos e dar prosseguimento às investigações. A princípio, Gloria e Justin tornam-se parceiros profissionais, mas a relação se aprofunda no decorrer da série. Em Cactus blood, o segundo romance, eles tornam-se amantes e, no início do terceiro, Black widow's wardrobe, Gloria se refere a Justin como "o homem com quem há algum tempo eu dividia meu trabalho investigativo, minha cama, meus sonhos" (CORPI, 1999, p.10) ${ }^{1}$. No caso da detetive chicana, esse relacionamento de igual para igual envolve uma total subversão dos valores tradicionais familiares mexicanos/chicanos, baseados na submissão da mulher ao marido. Gloria não enfrenta a oposição da família ou da sociedade porque decidiu seguir a carreira de detetive somente depois de se dedicar com afinco ao papel de esposa e mãe. Em nenhum momento ela escolhe deixar de lado a vida com o marido e a filha para se tornar uma detetive pro- 
fissional, ou seja, trocar a esfera privada pela pública. É apenas quando as circunstâncias da vida a deixam sozinha que ela decide retomar o trabalho de investigação que havia abandonado.

A questão da obrigação da mulher chicana em relação à família é tão forte que um dos grandes mitos da cultura é $L a$ Llorona. A imagem de La Llorona refere-se às mulheres cujos filhos foram mortos ou àquelas que por si próprias mataram ou abandonaram os filhos. Os espíritos dessas mulheres vagam sem conseguir descanso, e seus gritos angustiados podem ser ouvidos durante a noite (REBOLLEDO, 1995, P.62-63).

Lucha Corpi faz uma referência explícita ao mito de $L a$ Llorona no personagem de Lillian Cisneros, a mãe do menino assassinado. Lillian se culpa por ter deixado o filho com a avó para participar da Moratorium March e sente-se responsável pela morte dele. Ela vaga pela casa sem conseguir chorar até que um dia desaparece pela manhã e é encontrada pelo marido junto a uma fonte na frente da casa, repetindo: "Essa é a minha fonte de lágrimas. [...] Vou me afogar nela. O que eu fiz?" (CORPI, 1992, p.38). Tempos depois, Gloria e sua amiga Luisa também têm uma visão de Lillian como La Llorona:

\section{[...] they heard Lillian murmur, "M'ijito, I'm coming." \\ "La Llorona", whispered Luisa as her trembling hand squeezed Gloria's arm, "It's spooky". (CORPI, 1992, p.174)}

Essas passagens remetem o leitor à importância da unidade familiar para a cultura chicana, e lembram que a obrigação primordial da mulher chicana é em relação à família e aos filhos. $\mathrm{O}$ uso do mito no romance não tem função didática, não pretende apontar caminhos a serem seguidos pelos leitores e, principalmente, leitoras. O romance apenas descreve o que seria a reação comum de uma mãe de origem mexicana que perdesse um filho nas circunstâncias relatadas - ela choraria a perda, sim, mas dificilmente deixaria de sofrer o peso da responsabilidade imposta pelos costumes e se culparia por ter deixado o filho aos cuidados de outra pessoa.

O mito de La Llorona ajuda a compreender a razão pela qual Gloria opta pela família em detrimento da investigação do caso. A detetive Gloria Damasco não se opõe à mulher chicana Gloria Damasco - pelo contrário, elas se complementam. A detetive é um desdobramento natural de uma mulher que desde a juventude já se preocupava com o bem-estar da comunidade chicana, era politizada, participante ativa do Movimento Chicano, engajada na luta pelo fim do preconceito racial.

Lucha Corpi efetiva a reviravolta na vida de Gloria - de mãe de família a detetive - por meio de uma mudança na voz narrativa em Eulogy for a brown angel. A primeira parte do ro- 
mance, ambientada em 1970, ano em que o crime é cometido, é narrada em primeira pessoa e no tempo passado, pela própria Gloria Damasco, e corresponde a um relato autobiográfico. Gloria é exposta a uma situação-limite, no caso a descoberta do corpo do menino assassinado, e se envolve emocionalmente com o inquérito policial instaurado para solucionar o crime. A investigação que ela inicia não é uma atividade profissional, mas sim uma necessidade interior de compreender a ruptura da ordem que se dá com a morte do menino e, posteriormente, com as mortes de Mando e Joel Galeano. É interessante notar que o crime aqui é visto como uma ruptura da ordem não apenas no âmbito familiar, mas social - o crime não é considerado uma ocorrência isolada, e sim o fruto de um contexto social mais amplo. Como o relato de Gloria é feito no passado, há uma garantia, senão de imunidade total da detetive, ao menos de que ela sobreviverá para narrar a sua história.

O fim da primeira parte do romance corresponde à virada na vida pessoal de Gloria. Há uma passagem de tempo de dezoito anos. Em 1988, Gloria já é viúva e sua filha está na universidade; assim, já não enfrenta mais o conflito pessoal de ter que escolher entre cuidar da família e prosseguir na investigação do crime. Uma vez cumpridas as obrigações familiares, ela está livre para seguir o caminho que escolher, e decide dedicar-se à solução do mistério em tempo integral. Ela conhece Justin Escobar, detetive profissional, e o convida para ser seu parceiro na investigação do crime. Essa segunda parte é narrada em terceira pessoa, também no tempo passado; corresponde, na trama do romance, a essa transição na vida pessoal de Gloria, e em termos literários, a uma passagem da narrativa autobiográfica para a narrativa policial propriamente dita. A mudança na voz narrativa acarreta um aumento do suspense e o fim da garantia de integridade física da detetive. Essa garantia se perde pois a narração passa a ser feita por um narrador externo, ainda que continue utilizando o tempo passado. Enquanto a própria Gloria narrava os fatos, havia garantia de sua sobrevivência para o leitor.

A falta de imunidade é uma característica que afasta Gloria dos detetives dos romances de enigma, como Dupin, Holmes e Poirot, além da própria Miss Marple, que não corriam riscos ao longo das investigações, e a aproxima dos detetives dos romances noir, como Spade e Marlowe, assim como de outras detetives femininas contemporâneas, como a V.I. Warshawski de Sara Paretsky. É importante notar que Gloria não opta pela independência / solidão tão comuns entre os detetives hardboiled de ambos os sexos - pelo contrário, suas relações familiares e tradições culturais permanecem inalteradas na medida do possível, tanto por meio da proximidade afetiva com a mãe e a filha e a manutenção de antigas amizades quanto pelo estabelecimento de um novo vínculo amoroso. Assim, mesmo se profissionalizando, Gloria não 
seria exatamente uma detetive hardboiled - poderíamos chamála 'medium-boiled', no sentido de que ela nunca rompe os laços com a família, os amigos e a comunidade. Não existe em Gloria a solidão tão típica do P.I.... Por outro lado, ao estabelecer um relacionamento amoroso com seu sócio Justin Escobar, ela foge do padrão convencional e opta por não se casar - cada um vive em sua casa e mantém sua independência, de modo que vê-se que ela também não acata mais toda e qualquer tradição chicana.

Ao longo do processo de solucionar os mistérios, Gloria conta com a ajuda de sua percepção extrassensorial, definida por Donna M. Bickford como um modo de saber alternativo à visão de mundo ocidental, que valoriza apenas a ciência baseada no pensamento cartesiano e ignora outros meios de saber. Bickford ressalta que o pensamento contemporâneo, ao trabalhar com a crítica da objetividade científica, já apontou que é virtualmente impossível alcançar a almejada objetividade, uma vez que os saberes que adquirimos e produzimos são filtrados pelas nossas posições sociais, histórias e narrativas nacionais, estejamos ou não conscientes desses filtros. Os romances de Corpi seguem essa premissa, embora traduzida de forma singular - na construção de sua protagonista, ela estabelece a percepção extrassensorial como um caminho para o conhecimento equivalente à abordagem científica tradicional (BICKFORD, 2005, p.99).

Desse modo, as experiências psíquicas, premonições e visões de Gloria se apresentam como outra característica que desconstrói a imagem do detetive hegemônico, pois ela não utiliza apenas o intelecto para resolver os mistérios. As visões vão contra o caráter positivista do romance policial tradicional, sobretudo o de enigma, uma vez que não podem ser explicadas pela razão nem por uma relação de causa e efeito. Como, além disso, Gloria também costuma se envolver emocionalmente nos casos que investiga, desafiando a técnica mais aceita de manter distância emocional como parte do modelo investigativo, Corpi valida a presença da emoção no trabalho do detetive, mas vai além. Ao invés de propor uma polarização entre racionalidade e emotividade, Corpi oferece uma alternativa diferente, qual seja, conjugar a intuição e a percepção extrassensorial como meio para se chegar ao conhecimento, subvertendo a epistemologia ocidental, que considera a lógica e a razão os únicos meios legítimos para se alcançar o conhecimento (BICKFORD, 2005, p.99).

Em um dos capítulos iniciais de Cactus blood, Gloria descreve a descoberta de seus poderes psíquicos e como lida com eles no dia-a-dia:

I was twenty-three when I'd first discovered I had an extrasensory awareness - my dark gift. Since then, I had known that I had no more control over its rhythms than I had over my heart's beating. Nonetheless, I had relentlessly fought not to have my reason clouded by this prescience in me. But I also realized that 
regardless of how I felt about my heightened perception, once the dreams and visions came I would be committed - like an unskilled cryptographer - to extract meaning from them and to act on the knowledge. (CORPI, 1995, p.32)

A princípio, Gloria não se sente à vontade com o seu dom, e demonstra uma certa ambivalência quanto a esse meio nada convencional de chegar ao conhecimento. Assim, ela busca explicações racionais que possam sustentar o conhecimento que adquire por meio das visões, como na passagem a seguir:

I purposely didn't mention any of my 'flying' experiences. I suppose I felt embarrassed since I had always sought rational explanations for anything that happened to me, using intuition to support reason rather than the other way around. (CORPI, 1992, p.30)

Logo, entretanto, Gloria começa a se dar conta das limitações impostas por essas 'explicações racionais', como, por exemplo, quando conta à sua amiga Luisa que não culpa seu marido Darío por não compreender ou dar valor às suas visões:

'He's a medical doctor. If I told him any of this, he probably would assume I'm on LSD or some other drug. I don't think Darío would understand this at all. [...] I'm not sure that I myself understand or accept what's been happening to me.'

[... 'There are things one may not understand, but, still, one accepts them. I don't know where poetry comes from, but I know I'm moved to write poetry and I accept that. [...] There are things that can't be grasped intellectually. Maybe all this seems strange because you don't rely much on your intuition and perception of people and things.' (CORPI, 1992, p.48)

Ao longo da conversa com Luisa, Gloria afirma que a incapacidade de Darío de compreender o que se passa vem do próprio sistema de crenças vigente. Como aponta Bickford, "a implicação clara é que o conhecimento científico, como um meio de saber, tem suas próprias falhas e pontos cegos" (BICKFORD, 2005, p.100).

O conhecimento psíquico, contudo, não é, para Gloria, um atributo simples ou pacífico, mas uma característica com que ela aprende a conviver e na qual vem, por fim, a confiar, ainda que de forma extremamente cuidadosa, como mostra a passagem seguinte, em que sua filha Tania a questiona a respeito das visões:

"You've been having visions again. [...] Does it have anything to do with that case you and Justin are working on?" [...]

"It would seem that way," I answered, trying to tell myself that I shouldn't be so sure my theory was right until I went out and got the evidence to support it. "I still have to prove it though. I have to make sure I'm not just fooling myself. It's the only way I can keep my sanity." (CORPI, 1995, p.41)

Essa necessidade de confirmação, entretanto, não diminui a importância do seu poder - Gloria encontra um ponto de 
equilíbrio entre a razão e a intuição em seu método investigativo, de forma que, quando Luisa a questiona "Quem vence?... A intuição ou a razão?" (CORPI, 1992, p.48), é Bickford quem responde que, obviamente, nenhum dos dois modos de conhecimento vence, pois não são mutuamente excludentes, e nenhum dos dois precisa ser privilegiado:

De fato, reconhecer como a razão e a intuição operam em situações específicas é o que permite a Gloria interrogá-las, e a si mesma, e por fim ver que esses modos de saber como ações inextricavelmente ligadas, mesmo que não explicitamente conectadas: a intuição a ajuda a desconstruir a racionalidade, e a racionalidade fundamenta suas percepções psíquicas. (BICKFORD, 2005, p.101)

Nesse mesmo romance, Lucha Corpi desconstrói explicitamente o trabalho investigativo positivista de Poirot e outros detetives tradicionais, em um diálogo entre Gloria e o policial Matthew Kenyon, no qual ele dá crédito também à intuição como um instrumento de que o detetive se vale:

"What makes you so sure? A hunch?" [...]

"You make it sound like a dirty word." He chuckled.

"I thought detecting was accomplished through the analysis of evidence and lots of legwork. Ze littel grray cells, mon ami. Doesn't a detective have to be a combination of Hercule Poirot and Phillip Marlowe?" [...] "Do you really believe in hunches?"

“Don't you?" (CORPI, 1992, p.76)

Complementando essa linha de raciocínio, Judy Maloof lembra que Gloria passa por um processo de aceitação gradual do seu dom, mas por fim o percebe como um meio único de resolver mistérios, que a distingue dos detetives tradicionais, conhecidos por seus talentos no emprego de métodos dedutivos e pensamento racional. As ferramentas de Gloria são seus sonhos e visões 'irracionais', que representam, no texto, realidades alternativas e subjetivas. (MALOOF, 2006)

As passagens a seguir exemplificam algumas das visões de Gloria. Na primeira, extraída de Eulogy for a brown angel, ela tem uma visão do assassino de Mando:

I was moving slowly through a dark place, a warehouse of sorts, hot and misty, as if someone had opened the valves of a steam locomotive. Except for Mando, who was moving away from me, the place was empty. Suddenly, a shadow, with an even darker face, came towards him out of nowhere. Then, I saw a knife in a gloved hand strike straight ahead - a precise incision, through which only a little amount of blood spilled. Mando reached to his chest, keeled over, and laid face down. The dark-faced shadow swiftly moved out of sight. Finally, silence and darkness enveloped the scene. (...) The darker face 
I'd seen in my vision a few minutes ago appeared to be greasy, like the face of a soldier or a guerrilla fighter who's trying to camouflage his presence. (CORPI, 1992, p.54; 56)

A segunda passagem, retirada da primeira página de Cactus blood, relata a visão que impulsiona Gloria a descobrir o mistério por trás da mulher crucificada a um cactus:

That's when I saw her. The woman. Naked. Her arms stretched up, tied to the fleshy leaves. Her legs together, bound to the stem. A slumping female Christ with a prickly-pear cactus cross on her back, shrouded in blood, bathed in amber moonlight.

Ever since, she haunts my vigil and dreams. I know I will not rest until I learn for whose sins she was sacrificed. (CORPI, 1995, p.11)

Também Black widow's wardrobe se inicia com uma visão de Gloria, ou melhor, um pesadelo recorrente:

A woman fans the fire in a stone stove. She wears a mid-length skirt underneath a huipil with embroidered red flowers. Her long hair streams down her back. Her back is to me and I cannot see her face. Her young daughter plays by her side. A brooding young man sits at the kitchen table, playing with a dagger, a gift from his father. Suddenly, without saying a word, he gets up, picks up the dagger, and walks towards the woman at the stove. He raises his hand. She turns. The fire flares up, and her hair catches on fire, then her clothes. (CORPI, 1999, p.1)

Quando vê pela primeira vez a Viúva Negra do título do romance, Gloria imediatamente reconhece a mulher do pesadelo. Porém, a essa altura de sua carreira investigativa - pois Black widow's wardrobe é o terceiro romance da série - ela já aceita o fato de que seus sonhos e visões constituem uma parte integrante do seu trabalho de detetive, e comenta:

The first time I laid eyes on Black Widow, walking down a dark street in the Mission District, I knew she was the woman in my recurring nightmare. Two days later, I helplessly realized that my feelings and dreams had become inextricably meshed with the threads of Black Widow's life. I knew that the visions would follow, and that I would give myself no choice but to work toward freeing myself from their hold. (CORPI, 1999, p.1)

É curioso notar que Gloria atribui seus poderes extrasensoriais - a percepção aguçada, a intuição, e o 'dom oculto' das visões e sonhos premonitórios - à sua herança mexicana. Assim, Maloof ressalta que por meio da caracterização dessa personagem, Lucha Corpi abre o gênero policial à diversidade cultural, oferecendo uma percepção não-eurocêntrica da realidade, que inclui e aceita como real o conhecimento que vem de fontes misteriosas e intangíveis como os sonhos, as visões, a intuição e a percepção extrassensorial (MALOOF, 2006). Em Black widow's 
wardrobe, em especial, essas experiências não-racionais se entrelaçam à presença de um mito fundamental da cultura chicana - La Malinche - para apresentar um enredo policial que subverte a lógica cartesiana da ficção detetivesca tradicional. Na trama do romance, a missão de Gloria é proteger a vida da personagem Licia Lecuona, que acredita ser a reencarnação de La Malinche, a amante e intérprete indígena de Hernán Cortés.

Bem pouco se conhece da verdadeira história de La Malinche, e nem mesmo seu verdadeiro nome se sabe ao certo. Malintzin Tenepal, La Malinche ou Doña Marina, a nobre asteca que supostamente traiu o seu povo ao tornar-se intérprete, amante e sobretudo aliada do conquistador espanhol Hernán Cortés na empreitada de tomar a capital asteca Tenochtitlán, é ainda hoje uma personagem controversa. Nascida em família nobre, Malintzin recebeu educação condizente com a sua posição social. Quando seu pai morreu, no entanto, sua mãe casou-se novamente e teve um filho. Decidida a torná-lo seu único herdeiro e a evitar disputas por herança e poder, ela forjou a morte da filha e vendeu-a como escrava aos maias Xicalango que, por sua vez, a ofereceram à tribo Tlaxalteca. Por conta dos sucessivos deslocamentos territoriais a que foi submetida em sua nova condição, ela, ainda muito jovem, teve contato com novas tribos e culturas, desenvolvendo assim sua capacidade lingüística para o aprendizado de novos idiomas. Quando Malintzin contava 14 anos, os conquistadores espanhóis obtiveram sua primeira vitória significativa em terras mexicanas. Ela foi-lhes então oferecida como presente, integrando um grupo de vinte moças, todas batizadas com nomes cristãos e distribuídas entre os oficiais da confiança de Hernán Cortés. Malintzin tornou-se Doña Marina e foi destinada a um dos oficiais. Seus talentos lingüísticos foram logo percebidos e utilizados pelos conquistadores e Cortés tomou-a então para si como amante, além de tradutora e intérprete. Ela tornou-se conhecida entre os soldados espanhóis como "la lengua", a tradutora, que se postava ao lado de Cortés não apenas traduzindo o que era dito, mas também inserindo conselhos a ambas as partes, convencendo muitas tribos a se entregarem sem luta, buscando acordos diplomáticos e alianças sempre que possível. (FITCH, s/d)

La Malinche passou à História do México como uma traidora. Aliando-se ao conquistador e permitindo a comunicação entre espanhóis, maias e astecas, pode-se considerar que ela realmente facilitou a conquista do território indígena mexicano pelos espanhóis. Sua missão consistia em traduzir as palavras que eram ditas, mas ela também oferecia conselhos e explicações que contribuíram para a transição de uma cultura indígena, principalmente asteca e maia, para uma cultura que mesclava características indígenas e espanholas. Ao mesmo tempo, é importante ressaltar que ela não escolheu juntar-se a Cortés, mas foi-lhe oferecida como um presente, uma escrava, alguém que 
deveria servir-lhe e cuja vontade a princípio não seria reconhecida nem levada em consideração.

Além de sua importância crucial como intérprete e mediadora para a vitória espanhola, La Malinche cumpriu um outro papel que também marcaria profundamente a história do povo mexicano - o de amante de Cortés. Os conquistadores espanhóis vieram para a América sem a companhia de suas esposas, pois não era comum entre as mulheres da época empreender tal tipo de viagem aventureira, e esse fato muito contribuiu para a miscigenação em terras mexicanas. Ao tornar-se mãe de um filho, Martín, cuja paternidade foi reconhecida pelo conquistador, La Malinche tornou-se simbolicamente a mãe do povo mexicano mestizo, a fundadora de uma nova raça, de uma nova nacionalidade, não mais espanhola ou asteca, mas mexicana. Ainda hoje, La Malinche é uma personagem histórica vista de forma paradoxal. Sua importância simbólica transcendeu sua existência histórica e ela tornou-se uma figura mítica para mexicanos e chicanos, os quais, no entanto, não compartilham um mesmo ponto de vista. Os mexicanos, partidários da visão tradicional (que ganhou força durante o movimento de independência do México, no século XIX), a consideram realmente uma traidora, aquela que entregou seu povo aos conquistadores, "uma metáfora cultural para tudo o que há de errado com o México" (KRAUSS, 1997). O próprio adjetivo malinchista guarda conotação pejorativa - é usado para designar aquele que trai o seu povo, e hoje se refere principalmente aos mexicanos que têm uma estreita ligação com o estilo de vida anglo-americano.

A visão expressa por Octávio Paz é o ponto de partida para praticamente todas as revisões que foram feitas do mito de La Malinche a partir do Movimento Chicano (PAZ, 1950). Norma Alarcón mostra que Paz foi o primeiro a subverter o mito tradicional de La Malinche e não considerá-la uma traidora (ALARCÓN, 1994, p.114). Malintzin seria simplesmente a mãe primitiva do povo mexicano, aquela que deu origem a uma nova raça - ainda que essa origem seja considerada 'impura', já que a mãe teria sido violentada pelo conquistador. Seguindo essa linha de raciocínio, Paz argumenta que as próprias origens mexicanas são baseadas na conquista, opressão e ilegitimidade. Desse modo, La Malinche torna-se parte integrante do imaginário mexicano - romper com esse mito seria romper com o passado e negar as próprias origens.

Ainda segundo a visão tradicional, traduzir para Cortés, facilitando o trabalho de conquista, e gerar um filho dele, dando início a uma nova raça, teriam inscrito o nome de Malintzin na História definitivamente como uma "tradutora, traidora" - aquela que traduz é também a que trai o seu povo, não apenas entregando-o nas mãos do conquistador para que seja escravizado, mas também gerando um filho que dará origem a um povo amaldiçoado, marcado pela traição. 
Norma Alarcón explica como os conceitos de tradutora e traidora se fundem na figura de La Malinche:

Malintzin suscita um fascínio misturado com asco, suspeita e tristeza. Como tradutora, ela é a mediadora entre culturas antagônicas e contextos históricos. Se presumirmos que a linguagem é sempre, de certo modo, metafórica, então qualquer discurso, oral ou escrito, pode implicar traição quando se nota que ele vai além de repetir o que a comunidade percebe como conceitos, imagens ou narrativas 'verdadeiros' e/ou 'autênti$\cos ^{\prime}$. O ato de traduzir, que freqüentemente introduz conceitos e percepções diferentes, desloca o conhecimento local e pode até mesmo lhe ser violento por meio da linguagem. (ALARCÓN, 1994, p.113)

No mesmo ensaio, Alarcón tece alguns comentários sobre um poema do romancista e poeta mexicano José Emilio Pacheco, intitulado "Traduttore, traditore", que também ajudam a compreender melhor a questão:

Os tradutores, que usam a linguagem como agente mediador, têm a habilidade, consciente ou inconsciente, de distorcer ou converter o evento, a emissão, o texto, a experiência 'originais', tornando-os assim falsos, 'impuros'. [...] Ao traduzir, converter, transformar uma coisa em outra, interpretar (todos significados sugeridos pelo dicionário) o 'original', a conexão supostamente clara entre palavras e objetos é rompida e corrompida. A corrupção que se dá por meio da mediação lingüística pode tornar o falante um traidor no ponto de vista dos outros - não simplesmente um traidor, mas um traidor da tradição representada no evento, emissão, texto ou experiência "originais". (ALARCÓN, 1994, p.117)

Ainda na visão de Alarcón, Malintzin é considerada uma traidora porque assume uma postura própria, independente do seu papel de mãe. Essa postura era vista como uma catástrofe, pois uma mulher da época só teria permissão para articular suas necessidades e desejos em nome de seus filhos, e não em seu próprio. Por falar em seu próprio nome, ela seria uma traidora também da função primordial da mulher - a maternidade. (ALARCÓN, 1994, p.113)

Tey Diana Rebolledo lembra que mitos e histórias heróicas são instrumentos comumente usados pelas culturas para criar modelos a serem seguidos, diferenciar comportamentos corretos dos incorretos, transmitir valores morais e identificar características consideradas desejáveis por um determinado grupo (REBOLLEDO, 1995, p.49). Durante o Movimento Chicano, muitas mulheres foram rotuladas malinches ou vendidas apenas por tomar parte ativa no Movimento, demonstrando que buscavam transformar seus papéis culturais, o que gerava um conflito com a obrigação social de desempenhar um papel feminino tradicional. Seus maridos e os homens chicanos em geral pressupunham que elas deveriam ficar em casa cuidando dos filhos, cabendo a eles 
participar de marchas e protestos. Na visão masculina, o povo chicano sofria opressão por igual; na visão feminina, entretanto, a mulher era oprimida não apenas pela sociedade anglo-americana, por ser chicana, mas também por seu povo, por ser mulher.

Tal situação contribuiu para que várias escritoras chicanas sobretudo a partir dos anos 80 - ficassem fascinadas pelo mito da mulher que transgrediu sua cultura e procurassem reler o mito, vingando La Malinche. Quando os mitos existentes não correspondem aos valores que se deseja transmitir, torna-se necessário então escolher um entre dois possíveis caminhos: criar um novo mito que atenda à demanda ou imbuir os modelos existentes de traços e características às vezes radicalmente diferentes dos originais (REBOLLEDO, 1995, p.49). Seguindo esse raciocínio, as escritoras chicanas começaram a revisitar mitos já existentes em busca de arquétipos que correspondessem à demanda por figuras femininas positivas, ativas e enérgicas. Assim, a leitura feita pelas mulheres chicanas do mito de La Malinche vai além dos aspectos mais superficiais da história e subverte a idéia de conotação machista perpetuada pela tradicional interpretação mexicana. De acordo com Rebolledo, La Malinche torna-se uma personagem a ser não apenas redimida, mas também transformada. (REBOLLEDO, 1995, p.64)

Sua habilidade de traduzir para Cortés é considerada de fundamental importância entre as chicanas, uma vez que elas compartilham desse ir e vir consciente entre duas línguas e duas culturas. Assim como La Malinche foi acusada de hispanizar a cultura indígena, a comunidade chicana carrega o peso da acusação de anglicizar a cultura mexicana. La Malinche transitava entre a cultura espanhola que se impunha aos povos indígenas conquistados e a cultura nativa que buscava sobreviver, enquanto as chicanas transitam entre a cultura anglo-americana dominante e a cultura chicana, composta também por elementos espanhóis, mexicanos e indígenas, que também luta para manter uma voz.

Torna-se difícil para muitas chicanas compactuar com a visão que considera La Malinche culpada por todos os males que afligem o México, traidora do seu povo e da sua raça. Uma mulher que é vendida como escrava pela própria família e oferecida como presente aos conquistadores seria mais uma vítima dos algozes que dizimaram o seu povo, ao invés de cúmplice da conquista. Apesar desse contexto, no entanto, as escritoras chicanas não vêem a figura de La Malinche como uma vítima passiva dos acontecimentos. O principal ponto de ruptura com Octávio Paz é exatamente o confronto entre a visão da mulher apresentada por ele - sexualmente passiva, violentada pelo conquistador - e a visão chicana, na qual ela é considerada uma mulher que exerceu o seu direito de escolha e optou pelo caminho da sobrevivência. Ao aliar-se a Cortés, traduzir para ele e possibilitar a negociação entre os conquistadores e as tribos em lugar da matança 
indiscriminada, ela teria salvo milhares de vidas e evitado uma aniquilação ainda mais completa das tribos indígenas do México. (REBOLLEDO, 1995, p.64-65)

No entanto, a visão defendida por Rebolledo quanto à posição de La Malinche como uma mulher que fez escolhas encontra críticas no ensaio de Norma Alarcón já previamente mencionado. Diz ela:

Na realidade, toda a noção de escolha, uma noção existencialista da filosofia anglo-européia do século $X X$, precisa ser problematizada a fim de se compreender os entraves com os quais vivem as mulheres de outras culturas, épocas e lugares. Ao tentar tornar Malintzin uma motivada 'produtora de história', del Castillo não está reconstruindo o próprio momento histórico de Malintzin tanto quanto a usando para ir de encontro ao discurso masculino contemporâneo e para projetar um sentido mais novo do 'eu' feminino, um sujeito dotado de fala, com uma visão totalmente moderna de consciência histórica. (ALARCÓN, 1994, p.121)

Alarcón mantém uma postura divergente tanto dos escritores mexicanos quanto das mencionadas escritoras chicanas. Para os escritores mexicanos, a questão da violência sexual é de suma importância, pois marca a condição ilegítima do povo mexicano. É interessante lembrar que a expressão "hijo de la chingada" é uma grande ofensa no México, uma referência clara a Malinche, a violentada. Já as escritoras chicanas nem mesmo mencionam esse tipo de violência em sua produção literária, mas valorizam um poder de escolha que Alarcón diz ser questionável. Em sua visão, ela poderia ter se aliado a Cortés até como uma forma de se proteger, de evitar sofrer violência.

É a essa figura histórica tão controversa que a investigação de Gloria a encaminha. Seus primeiros passos a levam a uma ex-companheira de prisão de Licia, que ganha a vida como vidente. Gloria a consulta, sob disfarce, na companhia de Nina, amiga de sua mãe, e ouve que a chave para desvendar o mistério que cerca a tentativa de assassinato que Licia sofreu está na própria morte da Malinche. Nina se oferece para ir às bibliotecas com Pita, a mãe de Gloria, fazer um levantamento de toda e qualquer informação disponível acerca da história de La Malinche.

Ao transformar La Malinche em parte essencial do mistério, Lucha Corpi pode resgatar essa figura histórica do México por meio das descobertas das personagens e dos comentários e conversas que se seguem. Como foi dito anteriormente, a cultura tradicional mexicana considera a Malinche traidora da sua raça, aquela que abriu caminho para que os espanhóis dizimassem o povo asteca. Hoje em dia, vários estudiosos chicanos têm procurado redimir a sua figura, ao mostrá-la como uma outra vítima da Conquista. É interessante notar que são justamente 
Pita e Nina que pesquisam o mito - por serem mais velhas, elas estariam supostamente mais próximas da visão tradicional da Malinche. As incursões das duas pelas bibliotecas, entretanto, abrem para elas uma nova percepção histórica - elas efetuam um reaprendizado da História por meio de fontes de pesquisa e informação chicanas. Assim, torna-se flagrante a injustiça feita a Malinche pela história mexicana:

My mother voiced her protest about the way Mexican historians had reviled La Malinche, presenting her as a traitor to her people. 'How about those Tlaxcalteca warriors who fought the Aztecs alongside Cortés's army?' she asked. 'No-o-o-o. They were men. Men do not betray'. (CORPI, 1999, p.73)

No diálogo que estabelece com a cultura chicana, a narrativa de Lucha Corpi não deixa sem revisão nem mesmo a posição do escritor mexicano Octavio Paz acerca da Malinche. Embora o ensaio de Paz tenha sido o estudo precursor para as revisões chicanas do mito, nem ele escapa às críticas feitas pelas novas pesquisadoras, pois, embora não a veja como traidora, mas como a mãe do povo mexicano, ainda assim a considera destituída de atuação, um objeto nas mãos do conquistador:

Octavio Paz is a great writer, but even he calls Malintzin la gran chingada. I didn't know that the word chingada means the Indian woman raped by the conqueror. No wonder we Mexicans consider it the worst of all insults. (CORPI, 1999, p.86)

Embora reconheçam o relativo poder de escolha da Malinche, é importante ressaltar que a visão da mãe de Gloria e sua amiga acerca do mito não é romantizada:

"At first, Cortés didn't want her and gave her to his favorite cap-
tain, Puertocarreño [sic]. But he soon found out that Malintzin
was not only good-looking and good-natured, she was smart
and knew many Indian languages. She also learned Spanish
very fast. Cortés sent Puertocarreño [sic] on an errand to Spain
and took Malintzin as his mistress..."
"I'm glad you're saying she was his mistress, not his girlfriend,
like you told me earlier," my mother interjected. "Really, Nina."
(CORPI, 1999, p.72-73)

Aparentemente, as novas pesquisadoras compartilham da visão de Norma Alarcón ao admitir que, ainda que ela tenha agido por sua própria vontade, essa seria apenas a opção reservada aos que são escravizados: escolher, entre dois males, o menor. Dá-se uma ruptura com a tradição, com base na reapropriação do mito da Malinche a partir dos escritores mexicanos e da tradição oral chicana. (ALARCÓN, 1994, p.118)

Nota-se que é grande a probabilidade de que os gostos e valores dos leitores para os quais Lucha Corpi escreve contradigam ideologicamente os gostos e valores do grande público leitor 
dos Estados Unidos, alinhado com as crenças, valores e atitudes hegemônicas da cultura dominante do país, que é branca.

Na série considerada neste trabalho, a práxis cotidiana assume um papel fundamental como forma de resistência da cultura abordada frente ao poder dominante; as práticas tornam-se táticas por meio das quais essas comunidades marginalizadas buscam uma (re)apropriação de seus espaços na sociedade - em termos políticos, sócio-econômicos e culturais. As atividades do dia-a-dia constituem o próprio espaço dessa investigação, e conduzem a um maior acesso ao poder - valendo-se da posição marginal que ocupam, nossa detetive pode questionar uma sociedade a cujas regulações e normas apenas aparentemente se submete.

\begin{abstract}
Everyday practices are a strong presence in detective series Brown Angel Mysteries, by Chicana writer Lucha Corpi, Based on Michel de Certeau's theory about everyday practices, developed in The practice of everyday life, this article aims at discussing how the activities of everyday life, such as housework and the myths and beliefs inherited from Mexican tradition, represent a way of opposing resistance to dominant social and cultural practices, as well as their political role as a tactic through which the marginalized communities represented seek to (re)appropriate a cultural, political, social and economic space, acquiring new meaning in the confrontation between the center of power and the periphery. Through the characterization of the series' protagonist, Gloria Damasco, Lucha Corpi opens the detective genre to cultural diversity, offering a non-eurocentric perception of reality, which takes for real knowledge that comes from intangible sources, such as dreams, visions, intuition and extra-sensory perception. These non-rational experiences and the presence of fundamental myths of Chicano culture - such as La Llorona and La Malincheintertwine to present a detective plot that subverts the Cartesian logic of traditional detective fiction.
\end{abstract}

Keywords: Chicano detective literature; everyday practices; myths

\title{
REFERÊNCIAS
}

BICKFORD, Donna M. A Praxis of Parataxis: Epistemology and Dissonance in Lucha Corpi's Detective Fiction. Meridians: feminism, race, transnationalism. Vol. 5, no. 2, 2005. p.89-103. 
CERTEAU, Michel de. A invenção do cotidiano: 1.Artes de fazer. Petrópolis: Vozes, 2005. 1a. ed. bras. 1994.

CORPI, Lucha. Eulogy for a brown angel. Houston: Arte Público Press, 2002. 1a edição 1992.

Cactus blood. Houston: Arte Público Press, 1995. . Black widow's wardrobe. Houston: Arte Público Press, 1999.

DILLEY, Kimberly. Busybodies, Meddlers and Snoops: The female hero in contemporary women's mysteries. [Contributions in Women's Studies, No.166]. Westport, CT: Greenwood Publishing Group, 1998.

FITCH, Nancy. Malinche - Indian Princess or Slavish Whore? An Overview. Disponível em: <http://faculty.fullerton.edu/nfitch/ nehaha/malinche.html> Último acesso em: 07/07/2012.

KRAUSS, Clifford. A Historic Figure is Still Hated by Many in Mexico. The New York Times. Mar.26, 1997. Disponível em: $<$ http://www.emayzine.com/lectures/la.htm> Último acesso em: 07/07/2012.

MALOOF, Judy. The Chicana Detective as Clairvoyant in Lucha Corpi's Eulogy for a brown angel (1992), Cactus blood (1996), and Black widow's wardrobe (1999). Ciberletras: Revista de crítica literaria y de cultura, n.15 (2006). Disponível online em <http://www.lehman. edu/ciberletras/v15/maloof.html> Último acesso em 07/07/2012.

PAZ, Octavio. Hijos de la Malinche. In: El laberinto de la soledad. México: Fondo de Cultura Económica, 1959. 1 ed. 1950.

REBOLLEDO, Tey Diana. From Coatlicue to La Llorona: Literary Myths and Archtypes. In: Women Singing in the Snow: A Cultural Analysis of Chicana Literature. Tucson \& London: The U of Arizona P, 1995. p.49-81. 